\title{
Effects of Smokeless Tobacco, Betel Quid and Areca Nut on Oral Mucosa
}

\author{
R. Sahitha
}

\begin{abstract}
Betel/areca nut/tobacco habits have been reviewed and described about their effects on oral mucos association with oral cancer and various oral cancer and various oral precancerous lesions and conditions. "Quid" defined as "a substance, or mixture of substances, placed in the mouth or chewed and remaining in contact with the mucosa, usually containing two basic ingredients tobacco and areca nut. The betel quid refers to any quid wrapped in betel leaf and is therefore a specific variety of quid. Quid-related lesions should be categorized conceptually into two categories: first, those that are diffusely outlined and second, those localized at the site where a quid is regularly placed. Additional or expanded criteria and guidelines were proposed to define, describe or identify lesions such as chewer's mucosa, areca nut chewer's lesion, oral submucous fibrosis and other quid-related lesions. A new clinical entity, betel-quid lichenoid lesion, was also proposed to describe an oral lichen planus-like lesion associated with the betel quid habit. . As an early sign of damage to the oral mucosa, chewers of $B Q$ with or without tobacco often develop clinically visible whitish (leukoplakia) or reddish (erythroplakia) lesions and/or stiffening of the oral mucosa and oral submucous fibrosis (OSF).
\end{abstract}

\section{Introduction:}

Oral mucosa response in different ways to quid. Quid is a substance or mixture of substances that is placed in the mouth, where it is sucked or actively chewed and thus remains in contact with the mucosa over an extended period. It usually contains one or both of 2 basic ingredients, tobacco and areca nut. ${ }^{1}$ Avarity of oral mucosal lesions and conditions hace been reported in association with quid and tobacco use. ${ }^{1.2}$ Quid are classified into three basic categories: 1.Quid with areca nut without tobacco products (pan or betel quid), 2.Quid with tobacco products without areca nut (chewing tobacco, moist and dry snuff), 3. Quid with both areca nut and tobacco products (gutkha). ${ }^{3}$ The specific components of this product vary between communities and individuals.

The Betel quid or pan is mixture of areca nut (Areca catechu), catechu (Acacia catechu), slaked lime (calcium oxide and calcium hydroxide) and several condiments according to taste, wrapped in a betel leaf (Piper betle). Pan placed between the teeth and the buccal mucosa, and is gently chewed or sucked over a period of several hours. ${ }^{1,4}$ The slaked lime acts to release an alkaloid from the areca nut, which produces a feeling of euphoria and well-being. ${ }^{5}$ Other substances of local preference may be added, such as grated coconut or a variety of spices, for example, aniseed, peppermint, cardamom and cloves.6 Variants of pan include use of sliced areca nut alone and addition of sweeteners to make the product particularly attractive to younger children, to whom it is sold under the names sweet supari, gua, mawa or mistee pan. Other variants such as kiwam, zarda and mitha pan (also known as gutkha) may contain a variety of substances, including tobacco. ${ }^{4,7}$

In india most habitual chewers of betel quid add tobacco. Tobacco may also be used as a component of paan is called as gutkha. This product is basically a flavoured and sweetened by mixture of areca nut, catechu and slaked lime with tobacco, this usage of gutkha is more carcinogenic and associated with oral diseases. The product is basically a flavoured and sweetened dry mixture of areca nut, catechu and slaked lime with tobacco (gutkha) or without tobacco (pan masala). ${ }^{1}$ These products have been strongly implicated in the recent increase in the incidence of oral submucous fibrosis, especially in the very young, even after a short period of use. This precancerous lesion, which has a high rate of malignant transformation, is extremely debilitating and has no known cure. The use of tobacco with lime, betel quid with tobacco, betel quid without tobacco and areca nut have been classified as carcinogenic to humans. ${ }^{3}$ Increase in oral cancer among the young due to increased consumption of the alternative chewing products gutkha and pan masala. Pan masala and gutkha have become very popular with all sections of Indian society, including school children. For most children, teenagers and women, cigarette smoking still remains taboo in India.

Smokeless tobacco is a method of intra oral application and represents a nonhomogenous group of compounds. ${ }^{8}$ The term smokeless tobacco also known as dip, plug, chew or spit tobacco, refers to both chewing tobacco (coarse cut) and snuff ( fine cut). ${ }^{9}$ Three types of smokeless tobacco are commonly manufactured : loose -leaf chewing tobacco, most snuff and dry snuff. ${ }^{10}$ Tobacco products which were usually consumed by a small section of the population are today part of the modern urban and rural lifestyle. 


\section{CARCINOGENS IN PAN MASALA AND GUTKHA INGREDIENTS:}

The main carcinogens in pan masala and gutkha are derived from their ingredients areca nut, lime, catechu and tobacco. Several carcinogens are derived from tobacco but also from areca nut . 11 Carcinogenic nitrosamines that could be derived from major ingredients of pan masala (areca nut) and gutkha (areca nut and tobacco). The carcinogenic TSNAs(Tobacco-specific nitrosamines), N'-nitrosonornicotine (NNN), 4-(N-methyl-N-nitrosamino)-1-(3-pyridyl)-1-butanone (NNK) and N-nitrosoanabasine (NAB), as well as the volatile nitrosamines $\mathrm{N}$ - nitrosodimethylamine and $\mathrm{N}$-nitrosodiethylamine, have been detected in the saliva of chewers of BQ with tobacco. ${ }^{12}$ Chemical products of smokeless tobacco is nicotine, nitrosamines, nitrosamine acids ,polycyclic aromatic hydrocarbons(PAHS), aldehydes and metals. ${ }^{13}$ Tobacco specific nitrosamines are formed from alkaloids during the processing of tobacco leaves. The average consumption in regular users of snuff is about 10-15 g per day. In general the snuff is kept in the oral cavity for several hours per day. ${ }^{14}$

\section{ORAL MUCOSAL LESIONS AND CONDITIONS:}

Habit of chewing or holding of pan masala and gutkha in oral cavity - allows absorption of nicotine and other carcinogens through oral mucosa. Orally absorbed nicotine also stays longer in the blood stream. As an early sign of damage to the oral mucosa, chewers of BQ with or without tobacco often develop clinically visible whitish (leukoplakia) or reddish (erythroplakia) lesions and/or stiffening of the oral mucosa and oral submucous fibrosis (OSF). Quid-related lesions should be categorized conceptually into two categories: first, those that are diffusely outlined and second, those localized at the site where a quid is regularly placed. Additional or expanded criteria and guidelines were proposed to define, describe or identify lesions such as chewer's mucosa, areca nut chewer's lesion, oral submucous fibrosis and other quid-related lesions. A new clinical entity, betel-quid lichenoid lesion, was also proposed to describe an oral lichen planus-like lesion associated with the betel quid habit.

\section{LEUKOPLAKIA:}

A precancerous lesion in the oral cavity has also been strongly associated with smokeless tobacco use both among young adults and adolescents. ${ }^{15}$ leukoplakia refers to a filmy white or yellow patch involving the oral mucosa. The patch may appear translucent or opaque and raised or ulcerated. It may be pumice like. Leukoplakia is a keratotic white patch or plaque that cannot be scraped off and cannot be characterized clinically or pathologically as any other diseases.

\section{ERYTHROPLAKIA:}

Erythroplakia appears as a patch with varying degress of erythema. It most commonly occurs on the floor of the mouth. The term erythroplakia is used for a clinically and histopathologically similar process that occurs on the oral mucosa. Similar to the definition for leukoplakia is a clinical term that refers to a "fiery red patch or bright red velvety plaques that cannot be defined clinically or pathologically as any other condition. ${ }^{16}$

\section{TOBACCO POUCH KERATOSIS:}

Tobacco pouch keratosis is a "'white keratotic oral mucosal changes " resulting from chronic use of smokeless tobacco [ST] . Tobacco pouch keratosis also referred as "spit tobacco keratosis " and formerly referred as "tobacco chewers white lesion '. It is a condition that results from spit tobacco being habitually placed in the muco buccal fold in the mandibular anterior or buccal regions. It is only seen where the mucosa is in direct contact with snuff or chewing tobacco and it is also called as snuff dippers keratosis and smokeless tobacco keratosis. ${ }^{5}$

Most common area of involvement is the Anterior mandibular vestibules followed by the posterior vestibules. The development of this lesion is strongly depends on early onset, frequency, type and brand of tobacco use, amount of daily usage and number of sites routinely used for tobacco placement. The surface of mucosa appears white corrugated or wrinkled area where the tobacco has been placed. ${ }^{5}$ Clinical features varies in relation to the type, brand, frequency and duration of use of smokeless tobacco. In some cases the mucosa appears gray or gray-white and almost translucent. Since the tobacco is not in the mouth during examination, the usually stretched mucosa appears fissured or rippled and a "pouch" is usually present. The white tobacco pouch may become leathery or nodular in long-term heavy users. This type of lesion takes between 1 to 5 to develop depending on the total hours of daily use and the amount of use. ${ }^{9}$

The histopathologic appearance of smokeless tobacco keratosis is not specific. Squamous epithelium is hyperkeratinized and acanthotic (Thickened spinous layer with or without intracellular vacuolization or "edema" of glycogen-rich superficial layer. Characteristic of smokeless tobacco induced lesion is parakeratic chevrons may be seen as pointed projections above or within superficial epithelial layer which is not found to be present 
in all the cases. ${ }^{16}$ Hyaline deposition has been noted with in connective tissue and salivary glands. Increased subepithelial vascularity and vessel engorgement often are seen. ${ }^{5}$ Epithelial dysplasia is uncommon in tobacco pouch keratosis.

\section{ORAL SUBMUCOUS FIBROSIS:}

OSF is predominantly caused by the use of areca nut. ${ }^{18}$ Besides being regarded as a precancerous condition; it is a seriously debilitating and progressive disease.

Marked by stiffening of the oral mucosa and development of fibrous bands, loss of elasticity of the mucosa results in a progressive restriction of mouth opening. Affected users experience a burning sensation of the oral mucosa, occasional mucosal ulceration, a peculiar marble-like blanching of the mucosa and palpable fibrous bands of the buccal mucosa, soft palate. Moreover, the frequency of chewing rather than the total duration of the habit was directly correlated with OSF. ${ }^{18}$ Oesophageal subepithelial fibrosis, an extension of oral submucosal fibrosis, was seen more frequently in patients who had consumed pan masala, gutka, areca nut, tobacco or a combination of some or all of these, with or without betel leaf.

The pathogenesis of OSMF is believed to be multifactorial. Factors that trigger the disease include consumption of chewing areca nut, chilies, nutritional deficiencies, and immunologic processes. Areca nut chewing is known to cause local trauma and injury to the oral mucosa due to its abrasive nature. This could be more severe in users of pan masala and gutkha due to their fine particulate nature, with the high probability of particle adhesion to the traumatized mucosa, leading to morphological changes and membrane damage. This continuous local irritation by pan masala, gutkha or areca nut can lead to injury related chronic inflammation, oxidative stress and cytokine production. Oxidative stress and subsequent Reactive oxygen species (ROS) generation can induce cell proliferation, cell senescence or apoptosis, depending upon the level of ROS production. During chronic exposure, these events can lead to preneoplastic lesions in the oral cavity and subsequently to malignancy. ${ }^{17}$

Characteristics of Oral Submucous Fibrosis are palpable fibrous bands in buccal mucosa and soft palate, tough, leathery texture of the mucosa, blanching of the mucosa (defined as a persistent, white, marblelike appearance of the oral mucosa, which may be localized, diffuse or reticular), accompanied by histopathologic features characteristic of OSF (atrophic epithelium with loss of rete ridges and juxta-epithelial hyalinization of the lamina propria and the underlying muscle).

Betel Chewer's Mucosa:

Betel chewer's mucosa is a condition of the oral mucosa in which, because of either direct action of the quid or the traumatic effect of chewing (or both), there is a tendency for the oral mucosa to desquamate or peel. Loose and detached white tags of tissue can also be seen and felt. ${ }^{1}$ The underlying areas assume a pseudomembranous or wrinkled appearance.

Quid-Induced Lesion:

A quid-induced lesion is a localized lesion of the oral mucosa corresponding to the regular site of placement of quid. It is characterized by one or more of the following characteristics: change in colour, wrinkled appearance, thickening of the mucosa, scrapable or non scrapable epithelial surface, and presence of ulceration. ${ }^{1}$

Areca-Nut-Related Lesion:

Areca nut chewers, like chewers of other kinds of quid, may have clinically healthy mucosa with no textural or colour changes. However, the buccal mucosa, either bilaterally or unilaterally, may show an illdefined whitish grey discoloration that cannot be rubbed off. ${ }^{1}$ In addition, the mucosa may show a rough, linenlike texture, and histologic examination reveals ortho-keratinized or parakeratinized epithelium.

\section{Betel Quid Lichenoid Lesion:}

A quid-induced lichenoid oral lesion has been reported exclusively among users of betel quid. ${ }^{19}$ It resembles oral lichen planus, but there are certain specific differences. The quid-induced lesions is characterized by the presence of fine, white, wavy, parallel lines that do not overlap or criss-cross, are not elevated and in some instances radiate from a central erythematous area. The lesion generally occurs at the site of placement of the quid. This lesion was originally described as a lichen-planus-like lesion, but it is now termed a betel-quid lichenoid lesion. ${ }^{1}$ This lesion may regress with decrease in the

frequency or duration of quid use or a change in the site of placement of the quid. There may be complete regression if the quid habit is given up.

\section{Conclusion:}


The oral mucosal lesion is generally influenced by the person's specific quid habits, and there seems to be a significant relationship between quid cessation and a decrease in the incidence rate of white lesions. No specific test is available to confirm whether a particular oral lesion was caused by the patient's quid habit. The diagnosis must be made on the basis of a history of repeated exposure to betel quid containing certain ingredients, the clinical appearance and the texture of the tissue (especially for OSF). Incisional biopsy is recommended, specifically biopsy of the most severely affected area (or any area of ulceration) to rule out squamous cell carcinoma. ${ }^{20}$ Histopathologic examination may show a dense, chronic inflammatory infiltrate with epithelial changes ranging from atrophy accompanied by hyperkeratosis to dysplasia to frank malignancy. The management of such oral lesions depends on the type of quid-related lesion. The first option is no treatment, accompanied by discontinuation of the betel quid habit and appropriate follow-up. Mild cases of OSF or patients with limited jaw opening that still permits reasonable eating abilities and access for oral hygiene and dental care may be treated without intervention but with a focus on quitting the quid habit. Severe cases can be successfully treated, with return to near-normal jaw opening, bycomplete excision and surgery using mucosal or nonvascularized split-thickness skin grafts of the affected areas. ${ }^{20}$ Successful prevention in the early stages of these conditions may lead to improvement in symptoms. However, when the patient continues his or her betel quid habit, the prognosis for an untreated lesion, regardless of its colour, degree of thickening, ulceration of the epithelial surface or presence of thick fibrous bands, is progressive worsening, with a high risk for squamous cell carcinoma.

\section{Reference:}

[1]. Zain RB, Ikeda N, Gupta PC, Warnakulasuriya KAAS, van Wyk CW,Shrestha P, and other. Oral mucosal lesions associated with betel quid, Areca nut and tobacco chewing habits: consensus from a workshop held In Kuala Lumpur, Malaysia, November 25-27, 1996. J Oral Pathol Med 1999; 28(1):1-4.

[2]. Yang YH, Lee HY, Tung S, Shieh TY. Epidemiologic survey of oral Submucous fibrosis and leukoplakia in aborigines of Taiwan. J Oral Pathol Med 2001; 30(4):213-9.

[3]. Sylvie Louise Avon, DMD, msc. Oral Mucosal Lesions Associated with Use of Quid. J Can Dent Assoc 2004;70(4):244-8.

[4]. Farrand P, Rowe RM, Johnston A, Murdoch H. Prevalence, age of onset and demographic relationships of different areca nut habits amongst children in Tower Hamlets, London. Br Dent J 2001;190(3):150-4.

[5]. Neville BW, Damm DD, Allen CM, Bouquot JE. Oral and maxillofacial pathology. 2nd ed. Philadelphia: W.B. Saunders Company;2002. p. 349-50.

[6]. International Agency for Research on Cancer. IARC monographs on the evaluation of the carcinogenic risk of chemicals to humans. Tobacco habits other than smoking; betel-quid and areca-nut chewing; and some related nitrosamines. Vol. 37. 291 pp. Lyon, France: IARC, 1985

[7]. Shah B, Lewis MA, Bedi R. Oral submucous fibrosis in a 11-year-old Bangladeshi girl living in the United Kingdom. Br Dent J 2001; 191(3):130-2.

[8]. Greenberg. Glick . Ship. Burket's oral medicine. $11^{\text {th }}$ edition,page 100-101.

[9]. Jagriti Gupta,Krishna kumar Gupta,Fajad mansoor samadi, Arpita Kabiraj. Smokeless tobacco and oral cancer- A review. Year 2012; volume3; issue2; page 74-78.

[10]. WarnaKulasuriya KA, Ralhan R. clinical, pathological, cellular and molecular lesions caused by oral smokeless tobacco-A review. J oral pathol med 2007; 36:63-77.

[11]. Hoffmann,D., Brunnemann,K.D., Prokopczyk,B. and Djordjevic,M.V. (1994) Tobacco-specific N-nitrosamines and areca-derived N-nitrosamines: chemistry, biochemistry, carcinogenicity and relevance to humans. J.Toxicol. Environ. Health, 41, $1 \pm 52$

[12]. Wenke,G., Rivenson,A., Brunnemann,K.D., Hoffmann,D. and Bhide,S.V.(1984) A study of betel quid carcinogenesis. II. Formation of Nnitrosamines during betel quid chewing. In O'Neill,I.K., von Borstel,R.C.,Miller,C.T., Long,J. and Bartsch,H. (eds), N-Nitroso Compounds:Occurrence, Biological Effects and Relevance to Human Cancer, IARC Scientific Publications no. 57. IARC, Lyon, pp. $859 \pm 866$.

[13]. Stepanov I. Jensen J, Hatsukami D, Hecht SS. New and traditional smokeless tobacco; comparison of toxicant and carcinogen levels.Nicotine Tob Res.2008;10:1773-1782.

[14]. Pershagen G. smokeless tobacco.Br Med Bull 1996;52;50-7.

[15]. Warnakulasuriya S. Smokeless tobacco and oral cancer. Oral Dis 2004;10:1-4.

[16]. Neville BW, Day TA. Oral cancer and precancerous lesions. CA Cancer J Clin 2002;52:195-215.

[17]. Auluck A, Rosin MP, Zhang L, Sumanth KN. Oral Submucous Fibrosis, a Clinically Benign but Potentially Malignant Disease: Report of 3 Cases and Review of the Literature. J Can Dent Assoc 2008;74(8):735-40.

[18]. Murti,P.R., Bhonsle,R.B., Gupta,P.C., Daftary,D.K., Pindborg,J.J. and Mehta,F.S. (1995) Etiology of oral submucous fibrosis with special reference to the role of areca nut chewing. J. Oral Pathol. Med., 24, 145 \pm 152 .

[19]. Daftary DK, Bhonsle RB, Murti PR, Pindborg JJ, Mehta FS. An oral lichen planus-like lesion in India betel-tobacco chewers. Scand J Dent Res 1980; 88(3):244-9.

[20]. Marx RE, Stern D. Oral and maxillofacial pathology. A rationale for diagnosis and treatment. Quintessence Publishing Co, Inc.; 2003.p. 317-9. 